\title{
Comparison of two different optical coherence tomography angiography devices in detecting healthy versus glaucomatous eyes - an observational cross-sectional study
}

\author{
A. R. Kee', V. C. H. Yip ${ }^{1}$, E. L. T. Tay ${ }^{1,2}$, C. W. Lim³ ${ }^{3}$ J. Cheng ${ }^{4}$, H. Y. Teo ${ }^{1}$, C. H. Chua ${ }^{1}$ and L. W. L. Yip ${ }^{1,5^{*}}$
}

\begin{abstract}
Background: To understand the differences between two different optical coherence tomography angiography (OCTA) devices in detecting glaucomatous from healthy eyes by comparing their vascular parameters, diagnostic accuracy and test-retest reliability.

Methods: A cross-sectional observational study was performed on healthy and glaucoma subjects, on whom two sets of OCTA images of optic disc and macula were acquired using both AngioVue (Optovue, USA) and Swept Source (Topcon, Japan) OCTA devices during one visit. A novel in-house software was used to calculate the vessel densities. Diagnostic accuracy of the machines in differentiating healthy versus glaucomatous eyes was determined using area under the receiver operating characteristic curve (AUROC) and test-retest repeatability of the machines was also evaluated.

Results: A total of 80 healthy and 38 glaucomatous eyes were evaluated. Glaucomatous eyes had reduced mean vessel density compared to healthy controls in all segmented layers of the optic disc and macula using AngioVue $(p \leq 0.001)$. However, glaucomatous eyes had higher mean vessel density on optic disc scans using Swept Source, with lack of statistically significant difference between healthy and glaucomatous eyes. The AUROC showed better diagnostic accuracy of AngioVue (0.761-1.000) compared to Swept Source (0.113-0.644). The test-retest reliability indices were generally better using AngioVue than Swept Source.

Conclusions: AngioVue showed better diagnostic capability and test-retest reliability compared to Swept Source. Further studies need to be undertaken to evaluate if there is any significant difference between the various machines in diagnosing and monitoring glaucoma.
\end{abstract}

Keywords: Optical coherence tomography angiography, AngioVue, Swept source, Glaucoma, Diagnostic, Vascular parameters, Vessel density, Reliability

\footnotetext{
* Correspondence: leonard_yip@ttsh.com.sg

'National Healthcare Group Eye Institute, Tan Tock Seng Hospital, Singapore, Singapore

${ }^{5}$ Lee Kong Chian School of Medicine, Nanyang Technological University, Singapore, Singapore

Full list of author information is available at the end of the article
}

C C The Author(s). 2020 Open Access This article is licensed under a Creative Commons Attribution 4.0 International License, which permits use, sharing, adaptation, distribution and reproduction in any medium or format, as long as you give appropriate credit to the original author(s) and the source, provide a link to the Creative Commons licence, and indicate if changes were made. The images or other third party material in this article are included in the article's Creative Commons licence, unless indicated otherwise in a credit line to the material. If material is not included in the article's Creative Commons licence and your intended use is not permitted by statutory regulation or exceeds the permitted use, you will need to obtain permission directly from the copyright holder. To view a copy of this licence, visit http://creativecommons.org/licenses/by/4.0/. The Creative Commons Public Domain Dedication waiver (http://creativecommons.org/publicdomain/zero/1.0/) applies to the data made available in this article, unless otherwise stated in a credit line to the data. 


\section{Background}

Optical coherence tomography angiography (OCTA) is a relatively new, non-invasive imaging modality that is becoming of increasing interest in glaucoma diagnostics. It allows assessment of depth-resolved vascular status by detecting motion contrast from red blood cells and serves as a quick, reproducible, and objective way to qualitatively and quantitatively show areas of altered perfusion in the eye $[1,2]$. As vascular dysfunction has been proposed as an etiology for glaucoma [3-6], where loss of retinal vessel density (either as a primary or secondary effect) has been linked to glaucoma development and progression, analysis of ocular blood flow can potentially be used as a means in diagnosing and monitoring patients with glaucoma. Several recent studies have demonstrated microvascular changes using OCTA in optic nerve head, peripapillary area and macular area in glaucomatous eyes [7-12]. In our own recent study, we have found that vessel density at both the disc and macular regions was significantly reduced in glaucomatous eyes compared to controls, and OCTA can demonstrate high diagnostic accuracy in discriminating between glaucoma and healthy subjects using vessel density [13].

There are many OCTA devices available and each manufacturer uses varying techniques to differentiate blood vessels by depicting change in OCT-signal induced by the moving red blood cells. These include but are not limited to: (1) Angiovue OCTA (Optovue RTVue XR Avanti, Optovue Inc., Fremont, CA, USA), which works based on split-spectrum amplitude decorrelation; (2) Swept Source OCT (DRI-OCT Atlantis OCT, Topcon Corporation, Japan), which works based on OCTA ratio analyses algorithm; (3) Zeiss AngioPlex (Cirrus HD-OCT 5000,Zeiss Meditec. Inc.), which works based on micro-angiography; (4) Spectralis OCTA (Heidelberg Engineering, Germany), which works based on fullspectrum amplitude decorrelation algorithm; (5) Prototype of AngioScan (RS-3000 Advance OCT, Nidek Co., Ltd., Japan), which works based on a complex-décor relation algorithm $[1,14,15]$.

Due to their technical differences, conversion of parameters and measured values between different instrument systems is difficult. This is perhaps the reason why there is paucity of literature on the comparison between different OCTA instruments in the analysis of vessel density.

In our study, we used 2 different OCTA machines, namely AngioVue and Swept Source OCTA, which are available in our institution, to study the vessel densities in glaucomatous and healthy eyes. We aim to (1) quantitatively evaluate and compare vascular parameters provided by two OCTA devices in glaucomatous and healthy eyes, (2) compare the diagnostic accuracy of vascular parameters in discriminating between glaucomatous and healthy eyes, and (3) compare the test-retest variability within patients.

\section{Methods \\ Study design and patient recruitment}

Patients with glaucoma and healthy patients without glaucoma (control group) were recruited from the ophthalmology clinics at Tan Tock Seng Hospital, Singapore, between April 2015 and April 2016. This study is an expansion of patients recruited from our previous studies $[13,16]$ which evaluated the microvascular density of optic nerve head and macula in healthy and glaucoma subjects using 1 OCTA device. This crosssectional, prospective, observational study was approved by the Institutional Review Board of the National Healthcare Group and was conducted in accordance to the ethical standards stated in the Declaration of Helsinki. Written informed consent for study participation was obtained from all subjects.

All eligible participants underwent a complete comprehensive ophthalmic examination and investigations, including visual acuity, intraocular pressure (measured via Goldmann applanation tonometry), slit lamp biomicroscopy and fundoscopy. All patients underwent standard automated perimetry (SAP) with Humphrey Field Analyzer Swedish Interactive Threshold Algorithm standard 24-2 (Carl Zeiss Meditec, Dublin, CA). All participants underwent imaging via two different OCTA machines over the peripapillary and macular region on the same day and by the same operator. Vascular parameters of each scan images, as well as the diagnostic accuracy and test-retest reliability of each machine were determined.

Diagnosis of glaucoma was made based on presence of characteristic glaucomatous optic disc changes, such as thinning or notching of optic disc rim and hemorrhages at neuroretinal rim, with no history of other ocular or systemic diseases causing optic nerve damage, and corresponding visual field defects shown via at least two reliable and consistently abnormal SAP. Healthy subjects, who were recruited as controls, had best corrected visual acuity of $6 / 12$ or better, intraocular pressure lower than $22 \mathrm{mmHg}$, normal-appearing optic disc and retina, and normal SAP.

The following exclusion criteria were used: (1) history of intraocular surgery or previous laser therapy (but history of laser or surgery performed for the treatment of glaucoma allowed in the glaucoma group) (2) co-existing ocular pathologies such as vascular or non-vascular retinopathies, non-glaucomatous optic neuropathy (3) coexisting ocular or systemic diseases known to produce visual field defect (4) subjects known to be pregnant at time of recruitment (5) subjects younger than 21 years of age. In cases where both eyes of a normal or 
Table 1 Baseline characteristics of control and glaucoma group

\begin{tabular}{|c|c|c|c|c|}
\hline & & $\begin{array}{l}\text { Control } \\
\text { (40 patients, } n=80 \text { eyes) }\end{array}$ & $\begin{array}{l}\text { Glaucoma } \\
\text { ( } 30 \text { patients, } n=38 \text { eyes) }\end{array}$ & $P$-value \\
\hline Age (mean year +/- SD) & & $44.8 \pm 12.8$ & $64.3 \pm 6.28$ & $<0.001$ \\
\hline \multirow{2}{*}{$\begin{array}{l}\text { Gender } \\
{[n(\%)]}\end{array}$} & Male & $17(42.5 \%)$ & $26(86.7 \%)$ & \multirow[t]{2}{*}{$<0.001$} \\
\hline & Female & $23(57.5 \%)$ & $4(13.3 \%)$ & \\
\hline \multirow{4}{*}{$\begin{array}{l}\text { Ethnicity } \\
{[n(\%)]}\end{array}$} & Chinese & $34(85.0 \%)$ & $26(86.7 \%)$ & \multirow[t]{4}{*}{0.773} \\
\hline & Malay & $2(5.0 \%)$ & $1(3.3 \%)$ & \\
\hline & Indian & $3(7.5 \%)$ & $1(3.3 \%)$ & \\
\hline & Others & $1(2.5 \%)$ & $2(6.7 \%)$ & \\
\hline \multirow{2}{*}{$\begin{array}{l}\text { Presence of cataract } \\
{[\mathrm{n}(\%)]}\end{array}$} & Yes & $6(15.0 \%)$ & $24(80.0 \%)$ & \multirow[t]{2}{*}{$<0.001$} \\
\hline & No & $34(85.0 \%)$ & $6(20.0 \%)$ & \\
\hline $\begin{array}{l}\text { Intraocular pressure } \\
\text { (mean } \mathrm{mmHg}+/-\mathrm{SD})\end{array}$ & & $13.64 \pm 2.72$ & $14.89 \pm 2.38$ & 0.018 \\
\hline HVF (mean MD +/- SD) & & - & $-8.51 \pm 6.98$ & - \\
\hline HVF (mean PSD +/- SD) & & - & $7.46 \pm 3.93$ & - \\
\hline $\mathbf{H V F}$ (mean VFI +/- SD) & & - & $80.53 \pm 17.17$ & - \\
\hline \multirow{2}{*}{$\begin{array}{l}\text { Type of glaucoma } \\
{[n(\%)]}\end{array}$} & Open angle & - & $33(86.8 \%)$ & - \\
\hline & Closed angle & - & $5(13.2 \%)$ & - \\
\hline
\end{tabular}

SD Standard deviation; HVF Humphrey visual field; MD Mean deviation; PSD Pattern standard deviation; VFI Visual field index

glaucomatous patient were eligible, both eyes from each patient were included in the study.

\section{Optical coherence tomography angiography Image acquisition}

The AngioVue Enhanced Microvascular Imaging System (Optovue, Inc., Fremont, CA, USA) uses an $840 \mathrm{~nm}$ wavelength diode laser source and has an A-scan rate of 70,000 scans per second [17]. Each OCTA volume consists of $304 \times 304 \mathrm{~A}$-scan with 2 consecutive B-scans captured at each fixed position before proceeding to the next sampling location. The split-spectrum amplitudedecorrelation angiography (SSADA) algorithm was used to capture motion-contrast blood flow images and provide high-resolution 3-dimentional visualisation of perfused posterior segment microvasculature.

The Swept Source OCTA (SS-OCTA) (DRI-OCT Atlantis OCT, Topcon Corporation, Japan) uses a $1050 \mathrm{~nm}$ wavelength system and has an A-scan rate of 100,000 scans per second. Each B-scan position was repeatedly scanned 4 times for OCTA processing using an evaluation version of the OCTA software. Swept Source OCTA uses a ratio method, named OCTA Ratio Analysis (OCTARA), in which the full spectrum is kept intact, as compared to SSADA, and hence allowing preservation of axial resolution. The principle of ratio method has been well explained by Stanga et al. [18].

We followed the manufacturers' recommended scanning technique to capture images. Subjects were positioned with good eye alignment, and steady gaze was maintained via the systems' internal fixation target. The two machines' auto-focus technology was used to provide accurate focus on the posterior segment structure (optic disc or macula) of interest. Subjects were advised to maintain stable head position and gaze during scanning, but allowed to rest, blink or reposition in between scans.

Each subjects had up to two images taken per peripapillary and macular region for assessment of repeatability. Imaging of optic nerve head was performed with $3.0 \times 3.0 \mathrm{~mm}$ scans centred on optic nerve head for both AngioVue and Swept Source OCTA machines whereas imaging of macula was obtained using $3.0 \times 3.0 \mathrm{~mm}$ and $6.0 \times 6.0 \mathrm{~mm}$ scans centred on fovea macular scan for AngioVue and Swept Source OCTA devices respectively. After each scanning process, the images were reviewed and filtered. Poor quality images, i.e. images with significant motion artifacts as evidenced by irregular vessel pattern or disc boundary on the en face angiogram, poor image clarity or poor signal strength (signal strength index $<40$ ), were excluded from the study.

\section{Segmentation and subdivision}

Both AngioVue and Swept Source softwares were able to perform automated layer segmentation of the optic disc and macular regions into specific areas or layers (Fig. 1). AngioVue segments optic disc scan (vitreous, radial peripapillary capillaries (RPC), nerve head, disc choroid) and macular scan (superficial retina, deep retina, outer retina, choroid) into 4 layers whereas 


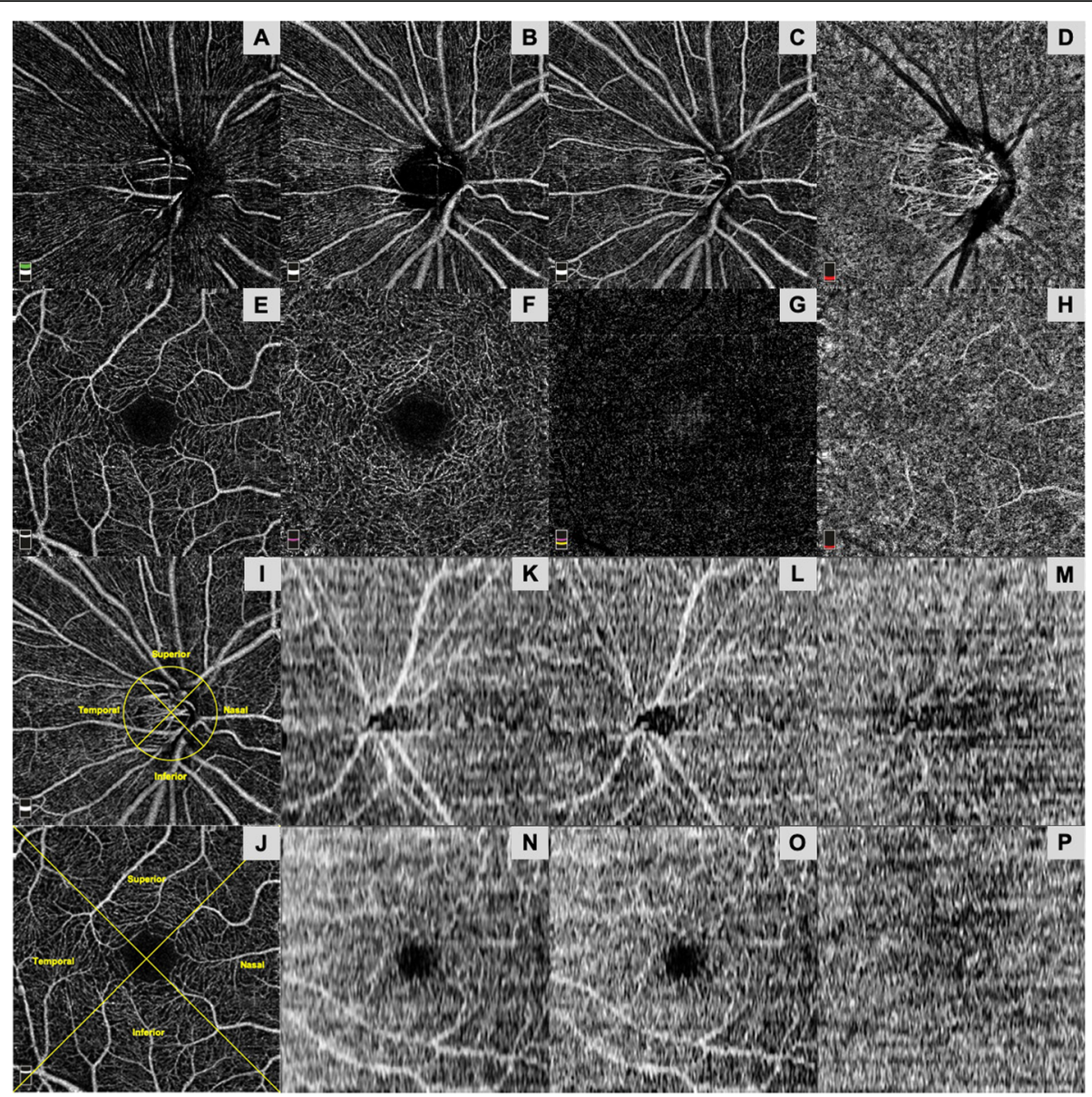

Fig. 1 Representative images from AngioVue and SweptSource optical coherence tomography angiography (OCTA) devices. Optic disc scans using AngioVue are divided into (a) vitreous, (b) radial peripapillary capillaries, (c) nerve head, and (d) disc choroid layers. Macular scans using AngioVue are divided into (e) superficial retina, (f) deep retina, (g) outer retina, and (h) choroid layers. Example of quadrant division of (i) optic disc scan and (j) macular scan using AngioVue. Optic disc scans (raw images shown) using SweptSource are divided into (k) superficial retina, (I) deep retina, and $(\mathbf{m})$ choroid layers. Similarly, macular scans (raw images shown) using SweptSource are divided into (n) superficial retina, (o) deep retina, and $(\mathbf{p})$ choroid layers

Swept Source segments both optic disc and macular scans into 3 layers (superficial retina, deep retina, choroid).

This generated detailed en face images, allowing visualisation of vascular details within these segmented boundaries. Each en face image layer was thereafter further subdivided into 4 equal quadrants, namely superior, inferior, temporal and nasal quadrant (Fig. 1). The four quadrants are determined based on a diagonal and antidiagonal line.

\section{Vessel density calculation}

Vessel density of each en face layer and quadrant of optic disc and macula was analysed using a novel inhouse developed software involving vessel detection and pixel counting. This is described in detail in our recent study [13].

\section{Statistical analysis}

Statistical analysis was performed using IBM SPSS Statistics version 22 (IBM Corp, New York, USA). Statistical significance was defined by $p$-value less than 0.05 . Descriptive statistics included mean and standard deviation for normally distributed variables.

To account the use of both eyes (right and left eye) from the same patient, we used linear mix model to compare between healthy and glaucomatous eyes while controlling for age and gender. In linear mixed model, the vessel density is treated as dependent variable, whereas, age, gender and grouping [glaucomatous vs healthy (control)] are fixed factors. The observation for each patient's right and left eye was treated as repeated observation, with repeated covariance type set as: Compound symmetric.

Diagnostic accuracy of both OCTA devices for differentiating between healthy and glaucomatous eyes was 
Table 2 Comparison of vessel density of optic disc scans between control and glaucoma group using AngioVue

\begin{tabular}{|c|c|c|c|c|c|}
\hline \multirow[t]{3}{*}{ Layers } & \multicolumn{4}{|c|}{ Age and gender-adjusted vessel density (\%) } & \multirow[t]{3}{*}{$P$-value } \\
\hline & \multicolumn{2}{|l|}{ Control $(n=80)$} & \multicolumn{2}{|l|}{ Glaucoma $(n=38)$} & \\
\hline & Mean \pm Standard Error & 95\% Confidence Interval & Mean \pm Standard Error & 95\% Confidence Interval & \\
\hline \multicolumn{6}{|l|}{ Vitreous } \\
\hline Inferior & $0.120 \pm 0.009$ & $0.101-0.138$ & $0.099 \pm 0.017$ & $0.066-0.133$ & 0.352 \\
\hline Superior & $0.094 \pm 0.010$ & $0.074-0.114$ & $0.056 \pm 0.016$ & $0.024-0.089$ & 0.090 \\
\hline Nasal & $0.099 \pm 0.010$ & $0.079-0.118$ & $0.062 \pm 0.015$ & $0.032-0.092$ & 0.078 \\
\hline Temporal & $0.100 \pm 0.008$ & $0.084-0.116$ & $0.073 \pm 0.013$ & $0.047-0.099$ & 0.123 \\
\hline Mean & $0.100 \pm 0.006$ & $0.087-0.112$ & $0.052 \pm 0.010$ & $0.032-0.073$ & 0.001 \\
\hline \multicolumn{6}{|c|}{ Radial peripapillary capillaries } \\
\hline Inferior & $0.188 \pm 0.009$ & $0.170-0.205$ & $0.069 \pm 0.015$ & $0.039-0.099$ & $<0.001$ \\
\hline Superior & $0.128 \pm 0.010$ & $0.108-0.147$ & $0.040 \pm 0.016$ & $0.008-0.073$ & $<0.001$ \\
\hline Nasal & $0.155 \pm 0.011$ & $0.133-0.176$ & $0.058 \pm 0.018$ & $0.021-0.094$ & $<0.001$ \\
\hline Temporal & $0.087 \pm 0.008$ & $0.071-0.104$ & $0.049 \pm 0.016$ & $0.018-0.081$ & 0.061 \\
\hline Mean & $0.139 \pm 0.006$ & $0.128-0.150$ & $0.042 \pm 0.009$ & $0.023-0.060$ & $<0.001$ \\
\hline \multicolumn{6}{|c|}{ Nerve head } \\
\hline Inferior & $0.220 \pm 0.009$ & $0.202-0.237$ & $0.117 \pm 0.015$ & $0.088-0.147$ & $<0.001$ \\
\hline Superior & $0.211 \pm 0.009$ & $0.193-0.229$ & $0.069 \pm 0.015$ & $0.039-0.099$ & $<0.001$ \\
\hline Nasal & $0.219 \pm 0.008$ & $0.202-0.235$ & $0.089 \pm 0.014$ & $0.061-0.117$ & $<0.001$ \\
\hline Temporal & $0.154 \pm 0.010$ & $0.135-0.173$ & $0.065 \pm 0.016$ & $0.034-0.097$ & $<0.001$ \\
\hline Mean & $0.200 \pm 0.005$ & $0.190-0.211$ & $0.084 \pm 0.009$ & $0.066-0.101$ & $<0.001$ \\
\hline \multicolumn{6}{|l|}{ Choroid } \\
\hline Inferior & $0.243 \pm 0.011$ & $0.222-0.265$ & $0.199 \pm 0.018$ & $0.164-0.234$ & 0.060 \\
\hline Superior & $0.303 \pm 0.013$ & $0.276-0.330$ & $0.179 \pm 0.012$ & $0.137-0.222$ & $<0.001$ \\
\hline Nasal & $0.256 \pm 0.012$ & $0.233-0.280$ & $0.184 \pm 0.020$ & $0.146-0.223$ & 0.007 \\
\hline Temporal & $0.227 \pm 0.013$ & $0.200-0.253$ & $0.144 \pm 0.022$ & $0.101-0.187$ & 0.005 \\
\hline Mean & $0.256 \pm 0.010$ & $0.236-0.276$ & $0.177 \pm 0.016$ & $0.145-0.209$ & 0.001 \\
\hline
\end{tabular}

evaluated by calculating the Area Under the Receiver Operating Characteristic (AUROC) curve. AUROC analyses were performed in Stata software Version 16 (StataCorp, College Station, Texas, USA) with the ROC regression method proposed by Alonzo and Pepe [19] and Janes et al. [20]. We employed a nonparametric ROC regression analysis (rocreg) with linear covariate adjustment (by specifying ctrlmodel (linear)) for patient age and gender, and cluster adjustment (by specifying cluster) for patient tested in each eye (right and left eye).

Repeatability was assessed by within-subject standard deviation (Sw) and within-subject coefficient of variation $(\mathrm{CV})$. The $\mathrm{Sw}$ was calculated as the square root of $(\mathrm{di} 2) / 2 \mathrm{n}$ where di is the difference between measurement for each individual and $n$ is the number of subjects. The CV (100 x Sw / overall mean) was calculated according to the procedure described by Bland and Altman.

\section{Results}

\section{Study population}

82 healthy control eyes and 39 glaucomatous eyes were initially included. Of these eyes, 3 were excluded due to poor quality OCTA images. A total of 80 control eyes and 38 glaucomatous eyes were studied.

Mean age of participants was $44.8+/-12.8$ and 64.3 $+/-6.28$ in the control and glaucoma group respectively $(p<0.001)$. Given that age can be a factor in affecting vessel densities, we adjusted for age in all our statistical analysis, including comparisons between healthy and glaucomatous eyes and AUROC. Baseline characteristics of both control and glaucoma patients are listed in Table 1 .

\section{Vessel density}

Statistically significant differences were found between healthy and glaucomatous eyes for almost all vessel density parameters using AngioVue (Tables 2, 3). For 
Table 3 Comparison of vessel density of macula scans between control and glaucoma group using AngioVue

\begin{tabular}{|c|c|c|c|c|c|}
\hline \multirow[t]{3}{*}{ Layers } & \multicolumn{4}{|c|}{ Age and gender -adjusted vessel density (\%) } & \multirow[t]{3}{*}{$P$-value } \\
\hline & \multicolumn{2}{|l|}{ Control $(n=80)$} & \multicolumn{2}{|l|}{ Glaucoma $(n=38)$} & \\
\hline & Mean \pm Standard Error & 95\% Confidence Interval & Mean \pm Standard Error & 95\% Confidence Interval & \\
\hline \multicolumn{6}{|c|}{ Superficial retina } \\
\hline Inferior & $0.126 \pm 0.004$ & $0.118-0.133$ & $0.082 \pm 0.005$ & $0.071-0.093$ & $<0.001$ \\
\hline Superior & $0.122 \pm 0.003$ & $0.115-0.128$ & $0.086 \pm 0.005$ & $0.077-0.096$ & $<0.001$ \\
\hline Nasal & $0.125 \pm 0.010$ & $0.104-0.146$ & $0.067 \pm 0.015$ & $0.037-0.098$ & 0.011 \\
\hline Temporal & $0.127 \pm 0.006$ & $0.115-0.139$ & $0.058 \pm 0.009$ & $0.040-0.075$ & $<0.001$ \\
\hline Mean & $0.116 \pm 0.002$ & $0.111-0.121$ & $0.076 \pm 0.004$ & $0.069-0.084$ & $<0.001$ \\
\hline \multicolumn{6}{|c|}{ Deep retina } \\
\hline Inferior & $0.239 \pm 0.007$ & $0.225-0.252$ & $0.118 \pm 0.010$ & $0.098-0.137$ & $<0.001$ \\
\hline Superior & $0.233 \pm 0.005$ & $0.222-0.243$ & $0.108 \pm 0.008$ & $0.093-0.124$ & $<0.001$ \\
\hline Nasal & $0.250 \pm 0.008$ & $0.235-0.265$ & $0.115 \pm 0.011$ & $0.092-0.138$ & $<0.001$ \\
\hline Temporal & $0.265 \pm 0.011$ & $0.243-0.287$ & $0.114 \pm 0.016$ & $0.082-0.146$ & $<0.001$ \\
\hline Mean & $0.244 \pm 0.006$ & $0.232-0.255$ & $0.117 \pm 0.008$ & $0.100-0.133$ & $<0.001$ \\
\hline \multicolumn{6}{|c|}{ Outer retina } \\
\hline Inferior & $0.159 \pm 0.012$ & $0.135-0.182$ & $0.091 \pm 0.017$ & $0.057-0.125$ & 0.008 \\
\hline Superior & $0.146 \pm 0.014$ & $0.118-0.173$ & $0.072 \pm 0.019$ & $0.034-0.110$ & 0.010 \\
\hline Nasal & $0.207 \pm 0.015$ & $0.177-0.237$ & $0.089 \pm 0.023$ & $0.043-0.134$ & 0.001 \\
\hline Temporal & $0.198 \pm 0.015$ & $0.166-0.229$ & $0.118 \pm 0.022$ & $0.074-0.163$ & 0.017 \\
\hline Mean & $0.186 \pm 0.009$ & $0.167-0.205$ & $0.089 \pm 0.013$ & $0.062-0.115$ & $<0.001$ \\
\hline \multicolumn{6}{|l|}{ Choroid } \\
\hline Inferior & $0.251 \pm 0.008$ & $0.236-0.267$ & $0.128 \pm 0.011$ & $0.105-0.150$ & $<0.001$ \\
\hline Superior & $0.245 \pm 0.009$ & $0.227-0.264$ & $0.134 \pm 0.013$ & $0.108-0.160$ & $<0.001$ \\
\hline Nasal & $0.240 \pm 0.013$ & $0.213-0.266$ & $0.139 \pm 0.019$ & $0.102-0.177$ & $<0.001$ \\
\hline Temporal & $0.253 \pm 0.009$ & $0.234-0.272$ & $0.133 \pm 0.014$ & $0.106-0.160$ & $<0.001$ \\
\hline Mean & $0.251 \pm 0.008$ & $0.235-0.266$ & $0.133 \pm 0.011$ & $0.111-0.154$ & $<0.001$ \\
\hline
\end{tabular}

glaucoma group, the age and gender-adjusted mean vessel density of optic nerve head at the choroid, nerve head, RPCs and vitreous was $0.177 \pm 0.016,0.084 \pm$ $0.009,0.042 \pm 0.009,0.052 \pm 0.010$ (Table 2) whereas that of macula at the level of choroid, outer retina, deep retina, and superficial retina was $0.133 \pm 0.011,0.089 \pm$ $0.013, \quad 0.117 \pm 0.008$ and $0.076 \pm 0.004$ respectively (Table 3). For both optic disc and macula scans, the mean vessel density of each segmented layer was reduced in glaucoma patients compared to healthy controls $(p \leq 0.001)$.

On the other hand, more variable results were found for OCTA parameters using Swept Source (Tables 4, 5). For glaucoma group, the mean vessel density of optic nerve head at the choroid, deep retina and superficial retina was $0.440 \pm 0.024,0.295 \pm 0.022$, and $0.294 \pm 0.026$ respectively whereas that of macula at level of choroid, deep retina and superficial retina was $0.319 \pm 0.021$, $0.236 \pm 0.022$, and $0.207 \pm 0.021$ respectively. The difference between healthy and glaucomatous eyes was not statistically significant, except for temporal quadrant $(p=0.040)$ and the mean vessel density $(p=0.048)$ of deep retina segment of optic disc $(p=0.040)$ as well as inferior quadrant $(p=0.001)$, temporal quadrant $(p=$ $0.003)$ and the mean vessel density $(p=0.007)$ of choroid layer of optic disc. Similar to the findings from the AngioVue, the mean vessel density of the macula scans was generally lower in glaucoma patients compared to healthy controls, except for temporal quadrants of superficial retina and deep retina layers. However, contrary to the findings from AngioVue, the mean vessel density of the optic disc scans was generally higher in glaucoma patients compared to healthy controls, except for inferior quadrant of superficial retinal layer of optic disc.

The AUROC for discriminating between healthy and glaucomatous eyes using AngioVue (Figs. 2, 3) was highest for RPC (0.990) followed by nerve head (0.986), 
Table 4 Comparison of vessel density of optic disc scans between control and glaucoma group using SweptSource

\begin{tabular}{|c|c|c|c|c|c|}
\hline \multirow[t]{3}{*}{ Layers } & \multicolumn{4}{|c|}{ Age and gender -adjusted vessel density (\%) } & \multirow[t]{3}{*}{$P$-value } \\
\hline & \multicolumn{2}{|l|}{ Control $(n=80)$} & \multicolumn{2}{|l|}{ Glaucoma $(n=38)$} & \\
\hline & Mean \pm Standard Error & 95\% Confidence Interval & Mean \pm Standard Error & 95\% Confidence Interval & \\
\hline \multicolumn{6}{|c|}{ Superficial retina } \\
\hline Inferior & $0.316 \pm 0.018$ & $0.281-0.351$ & $0.273 \pm 0.030$ & $0.313-0.432$ & 0.156 \\
\hline Superior & $0.241 \pm 0.019$ & $0.202-0.279$ & $0.270 \pm 0.033$ & $0.204-0.335$ & 0.500 \\
\hline Nasal & $0.181 \pm 0.016$ & $0.149-0.213$ & $0.251 \pm 0.031$ & $0.190-0.312$ & 0.074 \\
\hline Temporal & $0.203 \pm 0.018$ & $0.167-0.240$ & $0.280 \pm 0.031$ & $0.217-0.342$ & 0.066 \\
\hline Mean & $0.235 \pm 0.015$ & $0.204-0.265$ & $0.294 \pm 0.026$ & $0.241-0.346$ & 0.089 \\
\hline \multicolumn{6}{|c|}{ Deep retina } \\
\hline Inferior & $0.266 \pm 0.016$ & $0.234-0.298$ & $0.331 \pm 0.026$ & $0.279-0.384$ & 0.065 \\
\hline Superior & $0.233 \pm 0.018$ & $0.196-0.270$ & $0.261 \pm 0.031$ & $0.198-0.323$ & 0.504 \\
\hline Nasal & $0.242 \pm 0.013$ & $0.215-0.269$ & $0.295 \pm 0.026$ & $0.244-0.347$ & 0.105 \\
\hline Temporal & $0.213 \pm 0.017$ & $0.180-0.246$ & $0.292 \pm 0.029$ & $0.234-0.351$ & 0.040 \\
\hline Mean & $0.238 \pm 0.012$ & $0.214-0.263$ & $0.295 \pm 0.022$ & $0.252-0.338$ & 0.048 \\
\hline \multicolumn{6}{|l|}{ Choroid } \\
\hline Inferior & $0.355 \pm 0.016$ & $0.322-0.388$ & $0.479 \pm 0.027$ & $0.424-0.533$ & 0.001 \\
\hline Superior & $0.339 \pm 0.019$ & $0.301-0.378$ & $0.394 \pm 0.032$ & $0.330-0.457$ & 0.202 \\
\hline Nasal & $0.355 \pm 0.018$ & $0.319-0.391$ & $0.426 \pm 0.031$ & $0.365-0.487$ & 0.079 \\
\hline Temporal & $0.351 \pm 0.017$ & $0.318-0.385$ & $0.463 \pm 0.028$ & $0.408-0.518$ & 0.003 \\
\hline Mean & $0.350 \pm 0.015$ & $0.321-0.379$ & $0.440 \pm 0.024$ & $0.391-0.489$ & 0.007 \\
\hline
\end{tabular}

Table 5 Comparison of vessel density of macula scans between control and glaucoma group using SweptSource

\begin{tabular}{|c|c|c|c|c|c|}
\hline \multirow[t]{3}{*}{ Layers } & \multicolumn{4}{|c|}{ Age and gender -adjusted vessel density (\%) } & \multirow[t]{3}{*}{$P$-value } \\
\hline & \multicolumn{2}{|l|}{ Control $(n=80)$} & \multicolumn{2}{|l|}{ Glaucoma $(n=38)$} & \\
\hline & Mean \pm Standard Error & 95\% Confidence Interval & Mean \pm Standard Error & 95\% Confidence Interval & \\
\hline \multicolumn{6}{|c|}{ Superficial retina } \\
\hline Inferior & $0.323 \pm 0.017$ & $0.288-0.358$ & $0.255 \pm 0.031$ & $0.194-0.315$ & 0.087 \\
\hline Superior & $0.188 \pm 0.013$ & $0.162-0.214$ & $0.131 \pm 0.023$ & $0.086-0.177$ & 0.057 \\
\hline Nasal & $0.196 \pm 0.015$ & $0.166-0.225$ & $0.181 \pm 0.028$ & $0.126-0.236$ & 0.669 \\
\hline Temporal & $0.260 \pm 0.016$ & $0.228-0.293$ & $0.269 \pm 0.031$ & $0.207-0.330$ & 0.831 \\
\hline Mean & $0.241 \pm 0.011$ & $0.218-0.264$ & $0.207 \pm 0.021$ & $0.166-0.248$ & 0.199 \\
\hline \multicolumn{6}{|c|}{ Deep retina } \\
\hline Inferior & $0.315 \pm 0.018$ & $0.280-0.351$ & $0.288 \pm 0.032$ & $0.224-0.351$ & 0.500 \\
\hline Superior & $0.201 \pm 0.017$ & $0.167-0.236$ & $0.176 \pm 0.029$ & $0.118-0.234$ & 0.504 \\
\hline Nasal & $0.240 \pm 0.016$ & $0.208-0.272$ & $0.207 \pm 0.029$ & $0.148-0.265$ & 0.375 \\
\hline Temporal & $0.263 \pm 0.017$ & $0.229-0.297$ & $0.281 \pm 0.032$ & $0.218-0.344$ & 0.654 \\
\hline Mean & $0.255 \pm 0.012$ & $0.230-0.279$ & $0.236 \pm 0.022$ & $0.193-0.280$ & 0.521 \\
\hline \multicolumn{6}{|l|}{ Choroid } \\
\hline Inferior & $0.357 \pm 0.015$ & $0.326-0.387$ & $0.328 \pm 0.027$ & $0.274-0.382$ & 0.415 \\
\hline Superior & $0.317 \pm 0.016$ & $0.286-0.348$ & $0.302 \pm 0.026$ & $0.250-0.354$ & 0.670 \\
\hline Nasal & $0.357 \pm 0.015$ & $0.327-0.387$ & $0.353 \pm 0.027$ & $0.300-0.407$ & 0.918 \\
\hline Temporal & $0.357 \pm 0.014$ & $0.329-0.386$ & $0.299 \pm 0.026$ & $0.48-0.350$ & 0.082 \\
\hline Mean & $0.347 \pm 0.012$ & $0.324-0.370$ & $0.319 \pm 0.021$ & $0.277-0.360$ & 0.292 \\
\hline
\end{tabular}




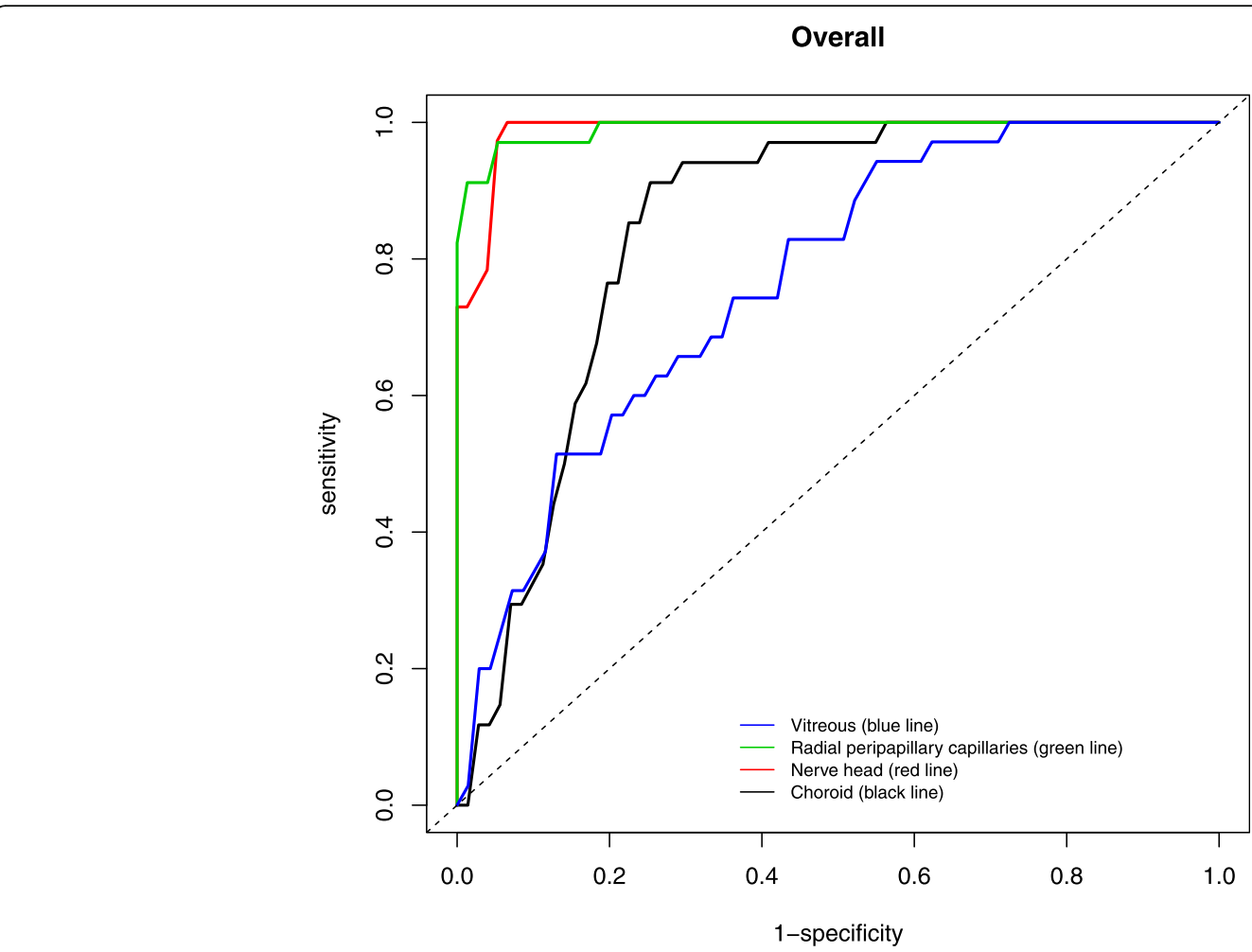

Fig. 2 Area under the receiver operating characteristic (AUROC) of optic disc scan using AngioVue

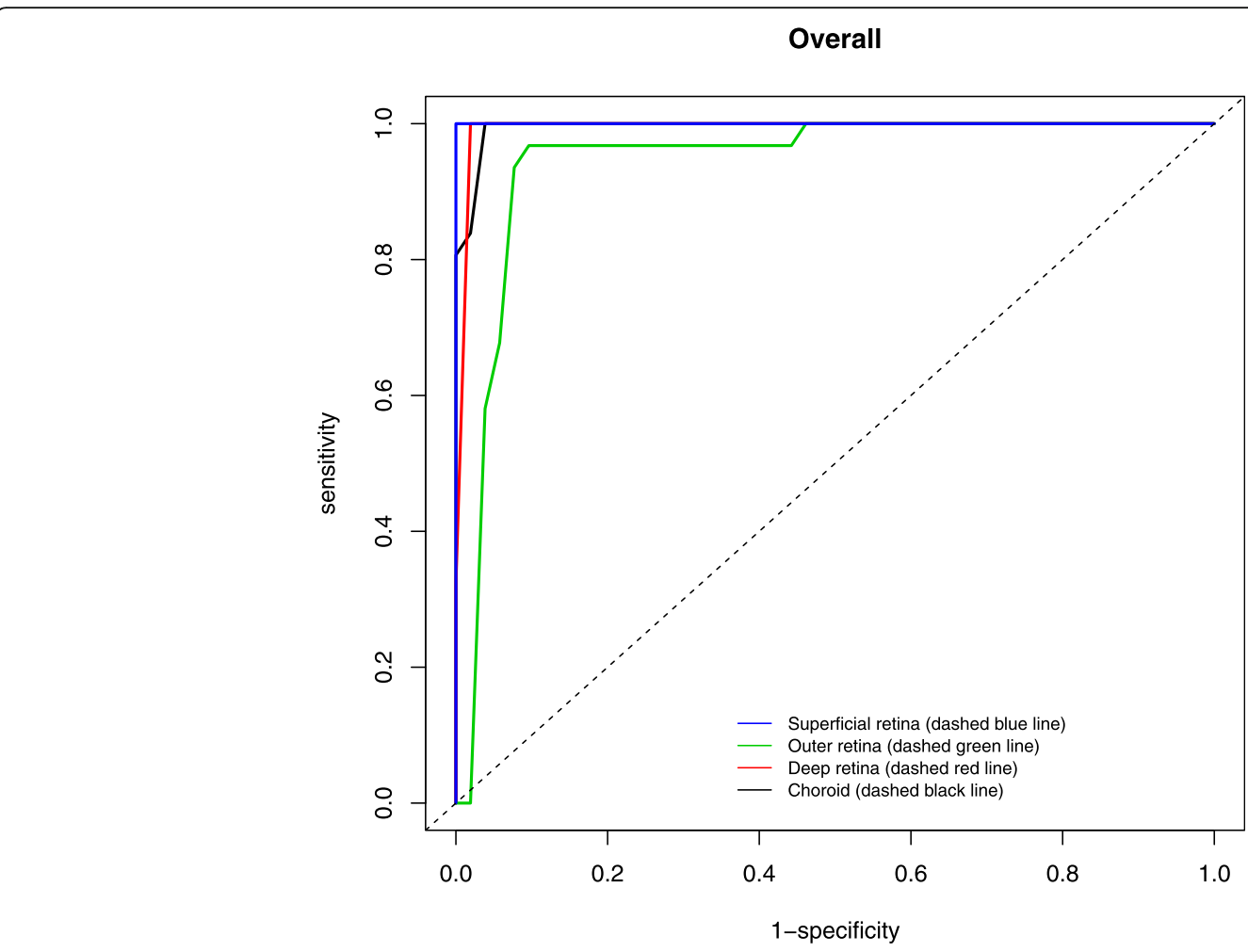

Fig. 3 Area under the receiver operating characteristic (AUROC) of macula scan using AngioVue 
Table 6 Area under the receiver operating characteristic (AUROC) values for optic disc and macula scans in discriminating healthy and glaucomatous eyes using AngioVue

\begin{tabular}{|c|c|c|c|c|c|}
\hline \multicolumn{3}{|c|}{ Optical Disc } & \multicolumn{3}{|l|}{ Macula } \\
\hline \multirow[t]{2}{*}{ Layers } & \multicolumn{2}{|c|}{ Age and Gender - adjusted } & \multirow[t]{2}{*}{ Layers } & \multicolumn{2}{|c|}{ Age and Gender - adjusted } \\
\hline & AUC & 95\% Confidence Interval & & AUC & 95\% Confidence Interval \\
\hline \multicolumn{3}{|l|}{ Vitreous } & \multicolumn{3}{|c|}{ Superficial retina } \\
\hline Inferior & 0.569 & $0.424-0.713$ & Inferior & 0.937 & $0.873-1.000$ \\
\hline Superior & 0.585 & $0.394-0.777$ & Superior & 0.954 & $0.897-1.000$ \\
\hline Nasal & 0.703 & $0.475-0.931$ & Nasal & 0.988 & $0.924-1.000$ \\
\hline Temporal & 0.692 & $0.521-0.863$ & Temporal & 0.994 & $0.977-1.000$ \\
\hline Mean & 0.761 & $0.616-0.907$ & Mean & 1.000 & $0.995-1.000$ \\
\hline \multicolumn{3}{|c|}{ Radial peripapillary capillaries } & \multicolumn{3}{|c|}{ Outer retina } \\
\hline Inferior & 0.920 & $0.853-0.987$ & Inferior & 0.818 & $0.592-1.000$ \\
\hline Superior & 0.830 & $0.693-0.968$ & Superior & 0.785 & $0.550-1.000$ \\
\hline Nasal & 0.907 & $0.822-0.992$ & Nasal & 0.882 & $0.743-1.000$ \\
\hline Temporal & 0.729 & $0.543-0.915$ & Temporal & 0.855 & $0.695-1.000$ \\
\hline Mean & 0.990 & $0.973-1.000$ & Mean & 0.934 & $0.825-1.000$ \\
\hline \multicolumn{3}{|c|}{ Nerve head } & \multicolumn{3}{|c|}{ Deep retina } \\
\hline Inferior & 0.864 & $0.755-0.973$ & Inferior & 0.984 & $0.953-1.000$ \\
\hline Superior & 0.947 & $0.885-1.000$ & Superior & 0.999 & $0.994-1.000$ \\
\hline Nasal & 0.931 & $0.886-0.976$ & Nasal & 0.980 & $0.940-1.000$ \\
\hline Temporal & 0.818 & $0.688-0.948$ & Temporal & 0.960 & $0.873-1.000$ \\
\hline Mean & 0.986 & $0.963-1.000$ & Mean & 0.987 & $0.961-1.000$ \\
\hline \multicolumn{3}{|l|}{ Choroid } & \multicolumn{3}{|l|}{ Choroid } \\
\hline Inferior & 0.654 & $0.484-0.825$ & Inferior & 0.985 & $0.956-1.000$ \\
\hline Superior & 0.866 & $0.764-0.968$ & Superior & 0.980 & $0.910-1.000$ \\
\hline Nasal & 0.694 & $0.551-0.836$ & Nasal & 0.837 & $0.642-0.972$ \\
\hline Temporal & 0.762 & $0.608-0.916$ & Temporal & 0.966 & $0.902-1.000$ \\
\hline Mean & 0.840 & $0.705-0.976$ & Mean & 0.993 & $0.961-1.000$ \\
\hline
\end{tabular}

choroid (0.840) and vitreous (0.761) for optic disc whilst highest for superficial retina (1.000), followed by choroid (0.993), deep retina (0.987) and outer retina (0.934) for macular area (Table 6). In contrast, the AUROC for distinguishing between healthy and glaucomatous eyes using Swept Source was generally lower (Figs. 4, 5), with highest being superficial retina (0.365), followed by deep retina (0.232) and choroid (0.113) layers of optic disc and choroid (0.644) followed by superficial retina (0.591) and deep retina (0.525) layers of macula (Table 7).

We used T-distributed Stochastic Neighbour Embedding (tSNE) plots (Figs. 6 and 7), which are based on a technique of dimensionality reduction for visualization of high-dimensional datasets, to show graphical representations of all statistical parameters of healthy and glaucomatous eyes in AngioVue and Swept Source. The tSNE plots show that datasets between healthy and glaucomatous eyes are easily distinguishable using AngioVue but not using Swept Source, which is consistent with our finding that there is a more promising distinguishing ability between glaucoma and control patients using AngioVue than that using Swept Source.

\section{Test retest variability}

For AngioVue, the within-subject standard deviation (Sw) of optic disc scans ranged from 0.022-0.042 for healthy eyes and 0.012-0.027 for glaucomatous eyes whereas coefficient of variation (CV) of optic disc scans ranged from 15 to $26 \%$ for healthy eyes and $15-33 \%$ in glaucomatous eyes (Table 8). Sw of macular scans ranged from $0.016-0.027$ for healthy eyes and $0.007-$ 0.012 for glaucomatous eyes while CV ranged from 7 to $14 \%$ for both healthy and glaucomatous eyes.

For Swept Source, Sw of optic disc scans was 0.0650.068 and $0.117-0.125$ and CV of $20-28 \%$ and $29-44 \%$ for healthy and glaucomatous eyes respectively (Table 9). 


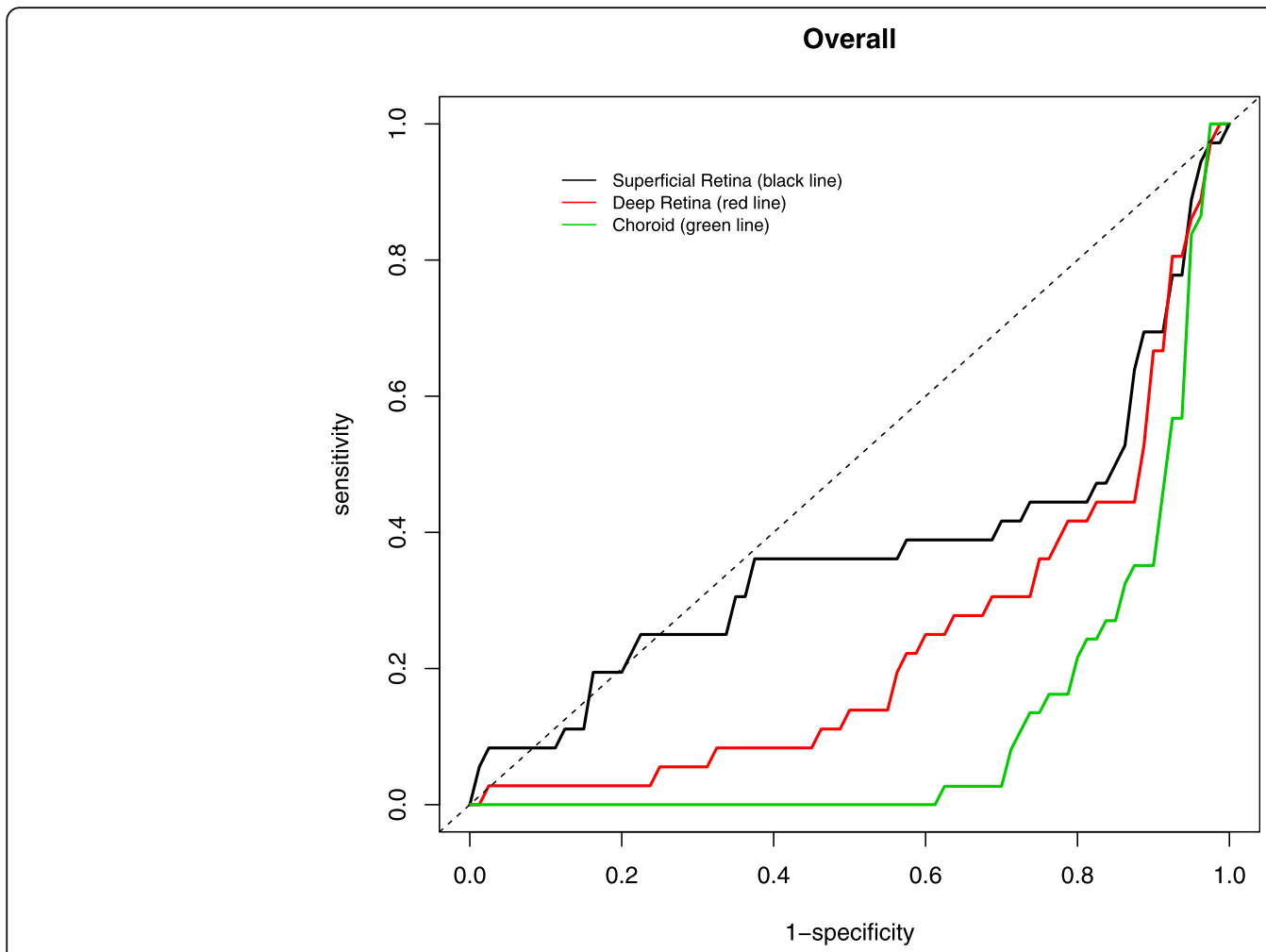

Fig. 4 Area under the receiver operating characteristic (AUROC) of optic disc scan using SweptSource

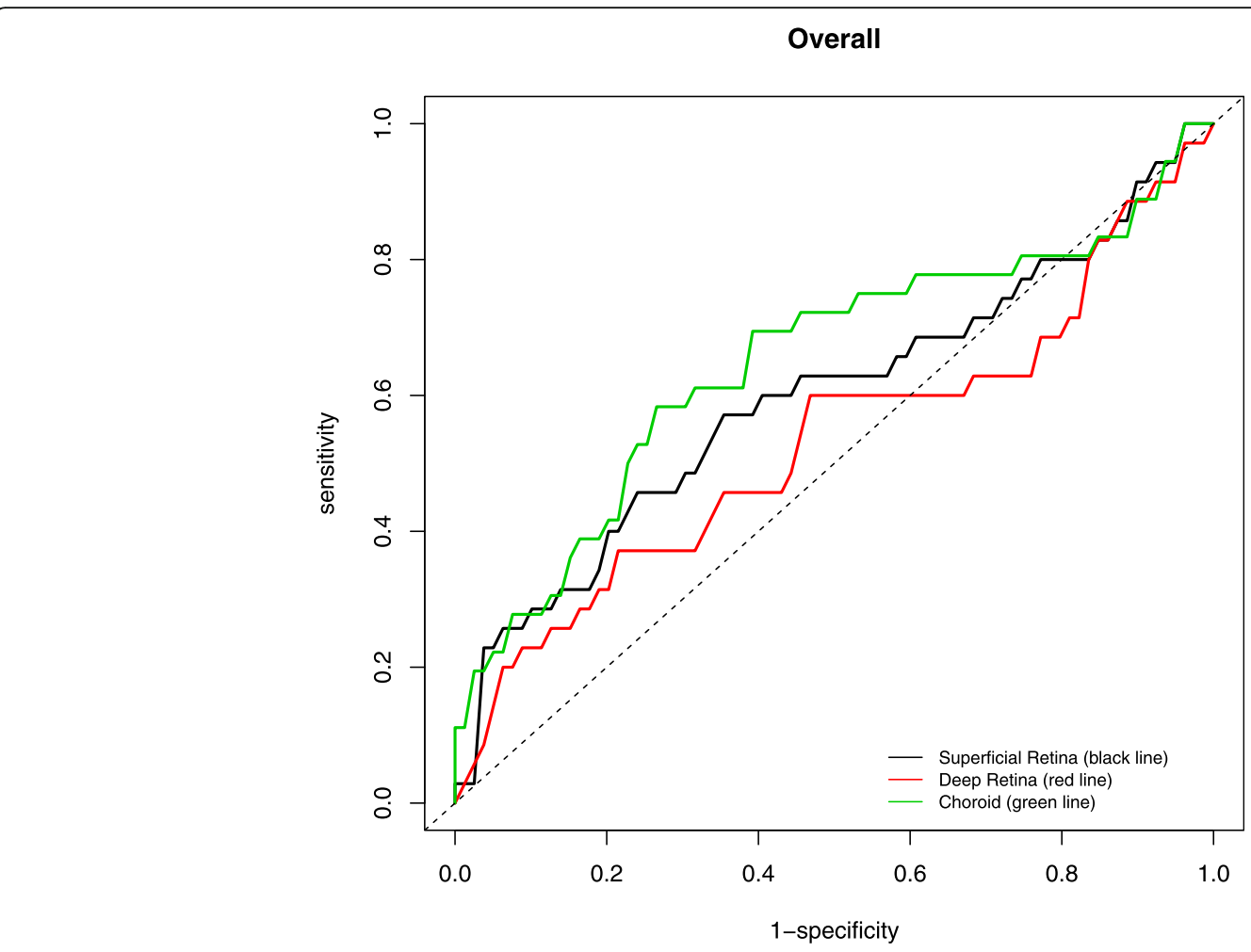

Fig. 5 Area under the receiver operating characteristic (AUROC) of macula scan using SweptSource 
Table 7 Area under the receiver operating characteristic (AUROC) values for optic disc and macular scans in discriminating healthy and glaucomatous eyes using SweptSource

\begin{tabular}{|c|c|c|c|c|c|}
\hline \multicolumn{3}{|c|}{ Optical Disc } & \multicolumn{3}{|l|}{ Macula } \\
\hline \multirow[t]{2}{*}{ Layers } & \multicolumn{2}{|c|}{ Age and Gender - adjusted } & \multirow[t]{2}{*}{ Layers } & \multicolumn{2}{|c|}{ Age and Gender - adjusted } \\
\hline & AUC & $95 \%$ Confidence Interval & & AUC & 95\% Confidence Interval \\
\hline \multicolumn{3}{|c|}{ Superficial retina } & \multicolumn{3}{|c|}{ Superficial retina } \\
\hline Inferior & 0.391 & $0.211-0.571$ & Inferior & 0.598 & $0.432-0.764$ \\
\hline Superior & 0.554 & $0.249-0.859$ & Superior & 0.694 & $0.512-0.877$ \\
\hline Nasal & 0.336 & $0.069-0.603$ & Nasal & 0.541 & $0.374-0.709$ \\
\hline Temporal & 0.294 & $0.088-0.500$ & Temporal & 0.369 & $0.210-0.527$ \\
\hline Mean & 0.365 & $0.082-0.649$ & Mean & 0.591 & $0.374-0.809$ \\
\hline \multicolumn{3}{|c|}{ Deep retina } & \multicolumn{3}{|c|}{ Deep retina } \\
\hline Inferior & 0.265 & $0.103-0.427$ & Inferior & 0.448 & $0.276-0.621$ \\
\hline Superior & 0.450 & $0.069-0.832$ & Superior & 0.643 & $0.440-0.846$ \\
\hline Nasal & 0.391 & $0.174-0.609$ & Nasal & 0.576 & $0.383-0.770$ \\
\hline Temporal & 0.239 & $0.082-0.397$ & Temporal & 0.363 & $0.208-0.517$ \\
\hline Mean & 0.232 & $0.000-0.472$ & Mean & 0.525 & $0.272-0.779$ \\
\hline \multicolumn{3}{|l|}{ Choroid } & \multicolumn{3}{|l|}{ Choroid } \\
\hline Inferior & 0.170 & $0.063-0.277$ & Inferior & 0.492 & $0.320-0.663$ \\
\hline Superior & 0.370 & $0.096-0.643$ & Superior & 0.606 & $0.400-0.813$ \\
\hline Nasal & 0.281 & $0.073-0.489$ & Nasal & 0.462 & $0.250-0.674$ \\
\hline Temporal & 0.235 & $0.035-0.436$ & Temporal & 0.660 & $0.491-0.829$ \\
\hline Mean & 0.113 & $0.000-0.311$ & Mean & 0.644 & $0.406-0.882$ \\
\hline
\end{tabular}

Similarly, repeatability was poorer for Swept Source than AngioVue for macular scans, where $\mathrm{Sw}$ was $0.106-0.115$ and $0.114-0.120$ while CV was $32-49 \%$ and $29-49 \%$ for control group and glaucoma group respectively.

\section{Discussion}

OCTA has been increasingly studied as a modality for diagnosing and monitoring patients with glaucoma, but very few, if any, have discussed the differences between different OCTA machines in their ability to diagnose various ocular diseases. This study aims to report the vessel density findings in healthy versus glaucomatous eyes using 2 different OCTA machines available in our institution, namely AngioVue and Swept Source.

Current evidence shows that lower vessel densities have been found in glaucomatous eyes compared to normal eyes in peripapillary area, optic disc and macular area [8-13, 21-23]. Similarly, we have found that vessel density is significantly reduced in glaucomatous eyes compared to that of healthy eyes using AngioVue machine. Contrary to previous studies, vessel density in glaucomatous eyes appeared to be greater than healthy eyes for optic disc scans when Swept Source machine was used for imaging. However, these differences were generally not statistically significant. Given that same participants underwent OCTA imaging via both
AngioVue and Swept Source, it is difficult to explain the stark difference in the intra-visit results between the two machines except for technical differences either in image acquisition or interpretation.

Many studies have shown high diagnostic accuracy of optical coherence angiography using vessel density, especially that of peripapillary area, to differentiate glaucomatous and healthy eyes density [10, 21, 22, 24-27]. Our study showed findings consistent with above for AngioVue, and the AUROC for discriminating glaucomatous from healthy eyes was better for AngioVue (mean ranging 0.761-0.990 for optic disc, 0.934-1.000 for macula) than Swept Source (mean ranging from 0.113-0.365 for optic disc, $0.525-0.644$ for macula).

Such differences in findings between different OCTA machines have been reported before. In a study by Rebolleda et al. [28], a comparison of two OCTA devices, AngioVue and AngioPlex, was performed in pseudoexfoliation (PXF) glaucoma versus primary open-angle glaucoma (POAG) and healthy subjects. In their study, only AngioVue detected a significantly lower capillary density in PXF glaucoma compared to POAG at similar glaucoma damage, and AngioVue-derived vascular parameters showed higher diagnostic capacity to discriminate among groups compared to AngioPlex. 


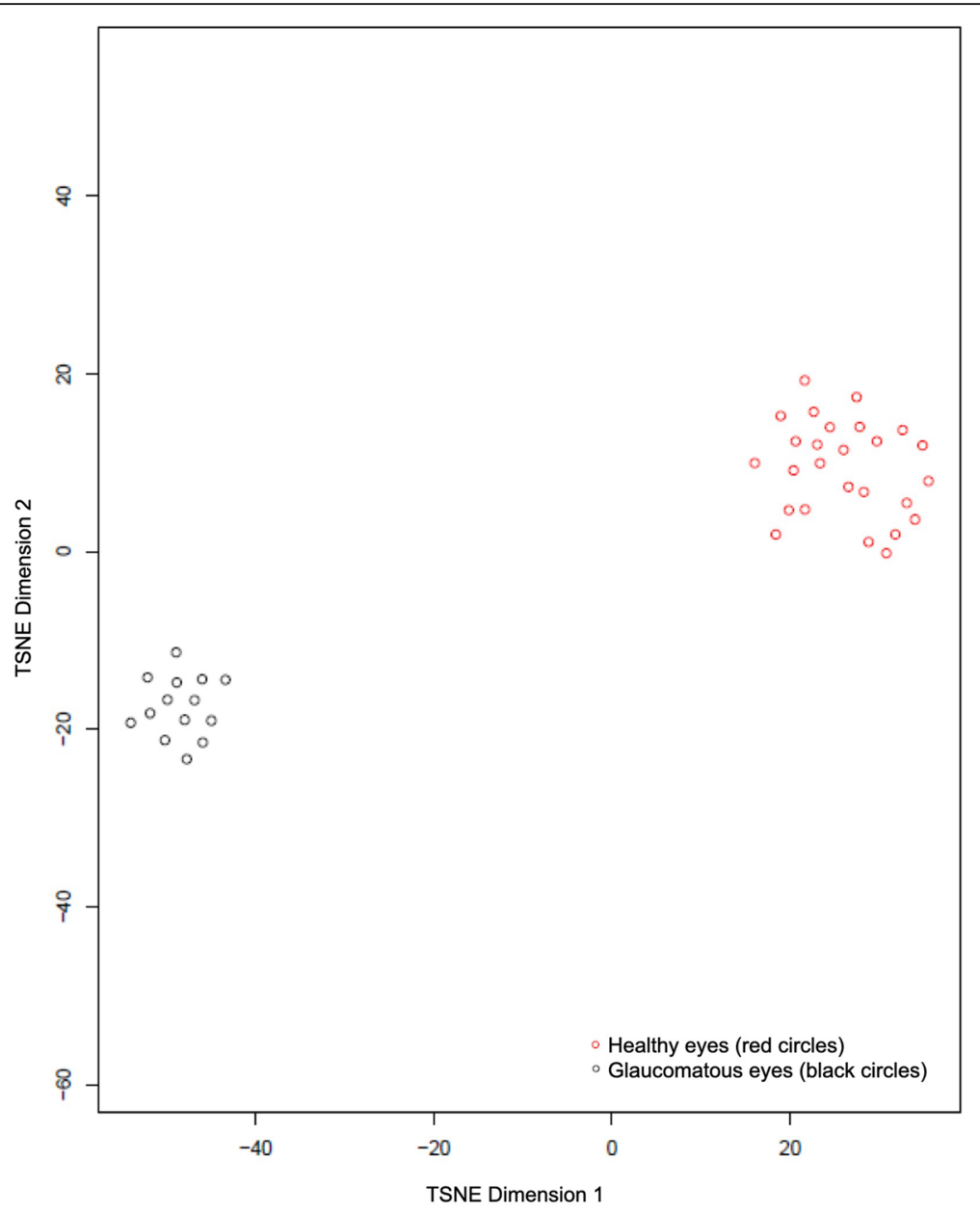

Fig. 6 T-distributed Stochastic Neighbour Embedding (tSNE) plot for healthy versus glaucomatous eyes using AngioVue

Differences in diagnostic ability between OCTA devices can be explained via several reasons. First, the boundaries of tissue segmentation (AngioVue being 4 segmented layers, Swept Source being 3 segmented layers) and the area evaluated (whole macular area evaluated by Swept Source was larger $6 \times 6 \mathrm{~mm}$ than that by AngioVue $3 \times 3 \mathrm{~mm}$ while optic disc area evaluated by both machines were similar $3 \times 3 \mathrm{~mm}$ ) differ between the two machines. Secondly, each modality employs different technology to quantify the motion contrast and also has different approaches to minimise motion artefacts and achieve optimal image quality with high resolution. Another study comparing 4 different OCTA modules also showed that there was better inter-grader agreement for Optovue compared to Topcon, and this was attributed to the fact that the grader reliability seemed to be associated with better quality of images and evaluated features [15]. Such technical differences between different OCTA machines may contribute to differing vessel density results in same subjects.
Our study also focused on test-retest reliability to determine if results are repeatable intra-visit for each of the machines. Such repeatability and reproducibility of OCTA has been described previously. In general, earlier studies demonstrated better repeatability of OCTA, with CV staying below $7 \%$ over a range of parameters, including those of macula, optic disc and peripapillary region, and for different OCTA algorithms used, be it splitspectrum amplitude decorrelation angiography (SSADA) algorithm, OCT-based microangiography (OMAG) or OCTA ratio analysis (OCTARA) [23]. However, for our study, there was higher CV up to $49 \%$ for healthy and glaucomatous eyes using either AngioVue or Swept Source. This shows much higher variability than current available evidence. A possible explanation is that our study includes a larger sample size compared to previous studies, making it difficult to reproduce low CVs to suggest good repeatability of OCTA. Secondly, current published studies had higher excluded signal strength index (SSI), where images with a SSI $<60$ [29], 50 [30], and 45 [28] were excluded from their study, whereas our study 


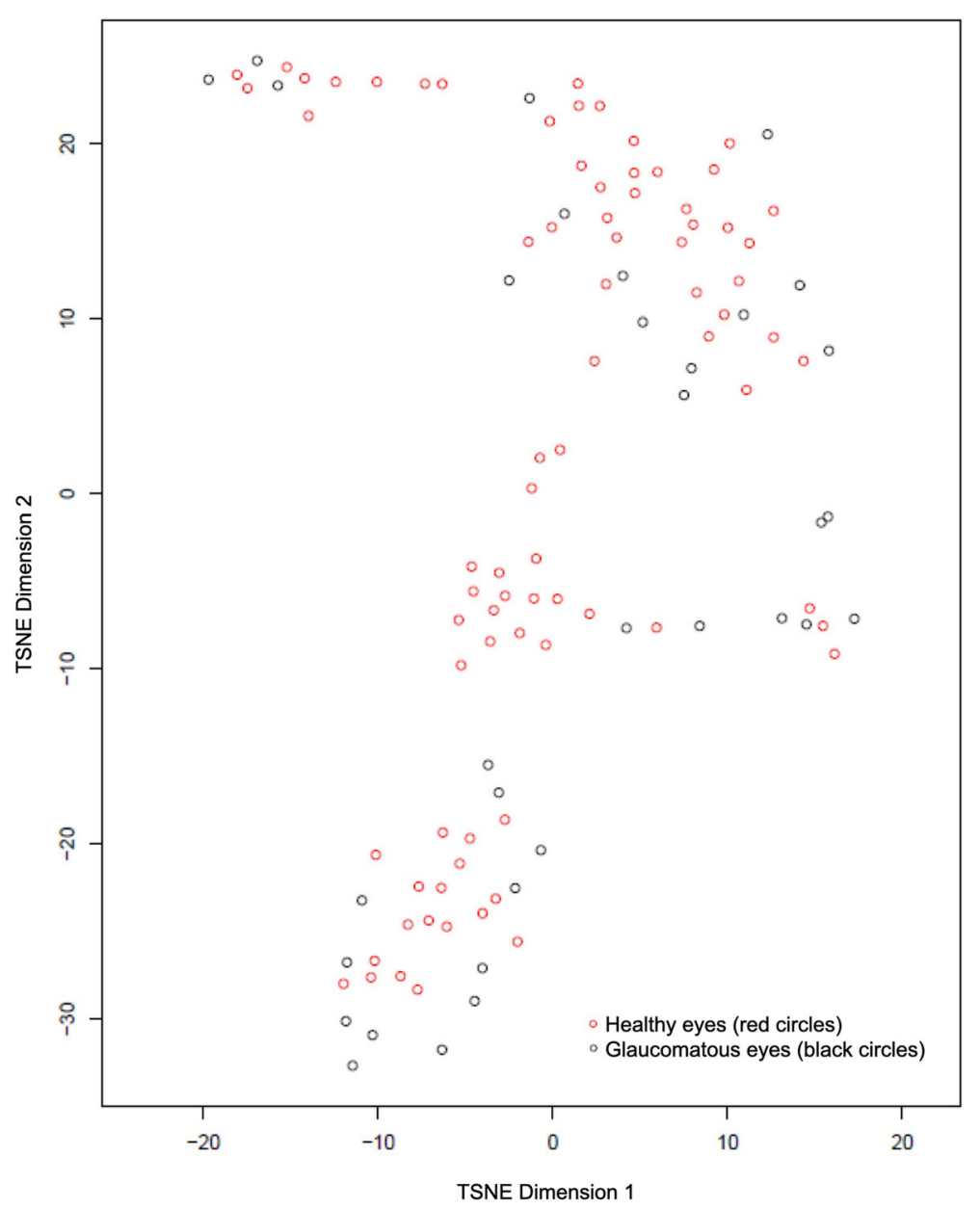

Fig. 7 T-distributed Stochastic Neighbour Embedding (tSNE) plot for healthy versus glaucomatous eyes using SweptSource

excluded images with SSI $<40$, which may affect the accuracy of data. Thirdly, due to technical differences, conversion of parameters and measured values between different instrument systems is difficult. Vessel density was analysed using a novel in-house developed software in this study. Contrary to the findings from AngioVue in this study and recent studies, the mean vessel density from Swept Source was generally higher in glaucoma patients compared to healthy controls for optic disc scans. On the other hand, $\mathrm{H}$ Akil et al. [31] reported even eyes with mild POAG could be differentiated from preperimetric glaucoma eyes, which also could be differentiated from normal eyes using Swept Source OCT angiography. These inconsistencies and high $\mathrm{CV}$ raises the question whether the novel in-house software was suitable in the vessel density calculation of Swept Source OCT angiography images.

Furthermore, we also found a difference in repeatability between two machines, where AngioVue was superior to Swept Source in its reproducibility of results. This suggests that the difference in technical algorithm of each device may affect the repeatability and reproducibility of intra-visit images. In fact, such difference in repeatability may also account for the finding above, where poorer repeatability found in Swept Source could have led to contradicting vessel density results and poorer discriminatory ability of Swept Source OCTA.

The findings from our study provide clinical significance in showing that there can be differing findings using different OCTA machines in monitoring optic disc and macular perfusion. While previous studies have shown that OCTA is a useful tool for monitoring vascular perfusion in ocular diseases, caution should still be exercised when interpreting data in view of significant test-retest variability within each machine and also across different machines.

Our study is not without its limitations. There was statistically significant difference in the demographics of our control and glaucoma group, where patients in control group had younger age than those in glaucoma group. Age in itself is an independent risk factor for microvascular changes in the eye [32], and other age- 
Table 8 Test-retest reliability of optic disc and macular scans of glaucomatous and healthy eyes using AngioVue

\begin{tabular}{|c|c|c|c|c|c|c|c|c|}
\hline Eyes & Scan & Layers & $\begin{array}{l}\text { Overall } \\
\text { mean }\end{array}$ & Sw & Sw $95 \% \mathrm{Cl}$ & CV & $\mathrm{CR}_{\mathrm{w}}$ & $\mathrm{CR}_{\mathrm{w}} 95 \% \mathrm{Cl}$ \\
\hline \multirow[t]{8}{*}{ Glaucoma } & Optic disc & Vitreous & 0.054 & 0.012 & $0.009-0.015$ & 22 & 0.033 & $0.025-0.041$ \\
\hline & & Radial peripapillary capillaries & 0.050 & 0.016 & $0.013-0.020$ & 33 & 0.046 & $0.035-0.057$ \\
\hline & & Nerve head & 0.095 & 0.016 & $0.013-0.020$ & 17 & 0.045 & $0.035-0.055$ \\
\hline & & Choroid & 0.178 & 0.027 & $0.021-0.033$ & 15 & 0.075 & $0.057-0.092$ \\
\hline & Macula & Superficial retina & 0.074 & 0.007 & $0.005-0.008$ & 9 & 0.018 & $0.014-0.023$ \\
\hline & & Deep retina & 0.106 & 0.011 & $0.008-0.013$ & 10 & 0.030 & $0.022-0.037$ \\
\hline & & Outer retina & 0.083 & 0.012 & $0.009-0.015$ & 14 & 0.033 & $0.025-0.041$ \\
\hline & & Choroid & 0.128 & 0.010 & $0.007-0.012$ & 7 & 0.027 & $0.020-0.033$ \\
\hline \multirow[t]{8}{*}{ Control } & Optic disc & Vitreous & 0.103 & 0.027 & $0.022-0.031$ & 26 & 0.074 & $0.062-0.087$ \\
\hline & & Radial peripapillary capillaries & 0.135 & 0.022 & $0.019-0.026$ & 17 & 0.062 & $0.052-0.072$ \\
\hline & & Nerve head & 0.197 & 0.029 & $0.025-0.034$ & 15 & 0.081 & $0.068-0.094$ \\
\hline & & Choroid & 0.264 & 0.042 & $0.035-0.049$ & 16 & 0.117 & $0.098-0.137$ \\
\hline & Macula & Superficial retina & 0.118 & 0.016 & $0.013-0.019$ & 14 & 0.045 & $0.036-0.053$ \\
\hline & & Deep retina & 0.251 & 0.017 & $0.013-0.020$ & 7 & 0.046 & $0.037-0.055$ \\
\hline & & Outer retina & 0.188 & 0.027 & $0.022-0.032$ & 14 & 0.075 & $0.061-0.089$ \\
\hline & & Choroid & 0.255 & 0.020 & $0.016-0.024$ & 8 & 0.056 & $0.045-0.066$ \\
\hline
\end{tabular}

Sw Within-subject standard deviation; $C l$ Confidence interval; $C V$ Coefficient of variation; $C R_{w}$ Coefficient of repeatability

related eye conditions such as cataract can develop in elderly subjects, as evidenced by greater number of patients with cataract in the glaucoma group, which can also affect angiographic result. Male to female ratio was higher in glaucomatous than healthy eyes, and gender differences have also been shown in ocular blood flow [33]. We tried to mitigate this by performing age- and gender-adjusted analysis of the data. Furthermore, direct comparison between the two OCTA machines are not possible as AngioVue segments into 4 different layers compared to Swept Source which segments into 3 layers instead. Thus, despite having used same in-house software to analyse the vessel density from the two different machines, direct comparison of the vessel density values across different layers, superficial to deep, is not possible due to the difference in segmentation of layers between the two machines. It is also possible that our in-house software may be biased toward one system and not the other, hence preferentially having better results with one than the other. Moreover, image acquisition and interpretation can be affected by poor quality scans. After elimination of these poor-quality images, some

Table 9 Test-retest reliability of optic disc and macular scans of glaucomatous and healthy eyes using SweptSource

\begin{tabular}{|c|c|c|c|c|c|c|c|c|}
\hline Eyes & Scan & Layers & $\begin{array}{l}\text { Overall } \\
\text { mean }\end{array}$ & Sw & Sw $95 \% \mathrm{Cl}$ & CV & $\mathrm{CR}_{\mathrm{w}}$ & $\mathrm{CR}_{\mathrm{w}} 95 \% \mathrm{Cl}$ \\
\hline \multirow[t]{6}{*}{ Glaucoma } & Optic disc & Superficial retina & 0.277 & 0.121 & $0.093-0.149$ & 44 & 0.335 & $0.258-0.412$ \\
\hline & & Deep retina & 0.278 & 0.117 & $0.090-0.143$ & 42 & 0.323 & $0.248-0.398$ \\
\hline & & Choroid & 0.432 & 0.125 & $0.097-0.153$ & 29 & 0.347 & $0.268-0.425$ \\
\hline & Macula & Superficial retina & 0.245 & 0.120 & $0.092-0.148$ & 49 & 0.332 & $0.254-0.410$ \\
\hline & & Deep retina & 0.254 & 0.117 & $0.090-0.145$ & 46 & 0.325 & $0.249-0.401$ \\
\hline & & Choroid & 0.389 & 0.114 & $0.088-0.140$ & 29 & 0.316 & $0.243-0.389$ \\
\hline \multirow[t]{6}{*}{ Control } & Optic disc & Superficial retina & 0.234 & 0.065 & $0.055-0.075$ & 28 & 0.181 & $0.153-0.209$ \\
\hline & & Deep retina & 0.241 & 0.065 & $0.055-0.075$ & 27 & 0.181 & $0.153-0.209$ \\
\hline & & Choroid & 0.347 & 0.068 & $0.058-0.079$ & 20 & 0.189 & $0.160-0.219$ \\
\hline & Macula & Superficial retina & 0.226 & 0.111 & $0.094-0.128$ & 49 & 0.307 & $0.259-0.355$ \\
\hline & & Deep retina & 0.241 & 0.115 & $0.097-0.133$ & 48 & 0.320 & $0.270-0.369$ \\
\hline & & Choroid & 0.333 & 0.106 & $0.089-0.122$ & 32 & 0.294 & $0.248-0.339$ \\
\hline
\end{tabular}

Sw Within-subject standard deviation; $C l$ Confidence interval; $C V$ Coefficient of variation; $C R_{w}$ Coefficient of repeatability 
participants only had one good quality scan which meant that we had to eliminate these participants from testretest reliability calculations. This results in further reduction in our sample size as well. Lastly, we have only compared between two machines out of the many OCTA machines that are currently available and we suggest further studies to be undertaken to compare different OCTA machines in the future.

\section{Conclusion}

OCTA is a new modality that provides high-speed, noninvasive, depth-resolved imaging of retinal and choroidal vasculature, and it has a great potential to expand our understanding, diagnosis and management of various ocular diseases including glaucoma.

There are currently no guidelines as to which machine and which specific scan protocol are best for clinical diagnosis and monitoring of glaucoma. To the best of our knowledge, our study is one of the first few of its kind to compare the diagnostic and repeatability indices in glaucoma versus controls using different OCTA machines. AngioVue consistently detected lower vessel density values in glaucomatous eyes compared to healthy eyes, had high diagnostic capability in distinguishing glaucomatous from healthy eyes and had better testretest reliability compared to Swept Source.

Prior to establishing OCTA as a new imaging modality for management of glaucoma, findings should be reproducible not just within the same OCTA machine but across different OCTA machines to allow standardization of results. We propose that further wide-scale longitudinal studies should be undertaken to evaluate if there is any significant difference between the various machines in diagnosing and monitoring ocular diseases.

\section{Abbreviations \\ AUROC: Area under the receiver operating characteristic; $\mathrm{CV}$ : Coefficient of variation; OCTA: Optical coherence tomography angiography; OCTARA: Optical coherence tomography angiography ratio analysis; RPC: Radial peripapillary capillaries; SSADA: Split-spectrum amplitude- decorrelation angiography; Sw: Within-subject standard deviation; tSNE: T- distributed stochastic neighbor embedding}

\section{Acknowledgements}

Not applicable.

\section{Authors' contributions}

KAR, YVCH and YLWL made significant contributions to the design of the work and writing of the manuscript. TELT, LCW and CJ acquired and analysed the data. THY and CCH analysed and interpreted the data. All authors read and approved the final manuscript.

\section{Funding}

Not applicable.

\section{Availability of data and materials}

The datasets used and/or analysed during the current study are available from the corresponding author on reasonable request.

\section{Ethics approval and consent to participate}

This study was approved by the Institutional Review Board of the National Healthcare Group and was conducted in accordance to the ethical standards stated in the Declaration of Helsinki. Written informed consent for study participation was obtained from all subjects.

Consent for publication

Not applicable.

\section{Competing interests}

The authors declare that they have no competing interests.

\section{Author details}

${ }^{1}$ National Healthcare Group Eye Institute, Tan Tock Seng Hospital, Singapore, Singapore. ${ }^{2}$ Department of Ophthalmology, Woodlands Health Campus, Singapore, Singapore. ${ }^{3}$ Department of Ophthalmology, Sarawak General Hospital, Kuching, Malaysia. ${ }^{4}$ Cixi Institute of Biomedical Engineering, Chinese Academy of Sciences, Ningbo, Zhejiang Province, China. ${ }^{5}$ Lee Kong Chian

School of Medicine, Nanyang Technological University, Singapore, Singapore.

Received: 26 April 2020 Accepted: 23 October 2020

Published online: 10 November 2020

\section{References}

1. Hagag AM, Gao SS, Jia Y, Huang D. Optical coherence tomography angiography: technical principles and clinical applications in ophthalmology. Taiwan J Ophthalmol. 2017;7:115-29.

2. Gao SS, Jia Y, Zhang M, Su JP, Liu G, Hwang TS, et al. Optical coherence tomography angiography. Invest Ophthalmol Vis Sci. 2016;57:OCT27-36.

3. Flammer J, Orgul S, Costa VP, Orzalesi N, Krieglstein GK, Serra LM, et al. The impact of ocular blood flow in glaucoma. Prog Retin Eye Res. 2002;21:359-93.

4. Grieshaber MC, Flammer J. Blood flow in glaucoma. Curr Opin Ophthalmol. 2005;16:79-83.

5. Nicolela MT. Clinical clues of vascular dysregulation and its association with glaucoma. Can J Ophthalmol. 2008:43:337-41.

6. Pasquale LR. Vascular and autonomic dysregulation in primary open-angle glaucoma. Curr Opin Ophthalmol. 2016;27:94-101.

7. Hollo G. Vessel density calculated from OCT angiography in 3 peripapillary sectors in normal, ocular hypertensive, and glaucoma eyes. Eur J Ophthalmol. 2016;26:e42-5.

8. Jia Y, Wei E, Wang X, Zhang X, Morrison JC, Parikh M, et al. Optical coherence tomography angiography of optic disc perfusion in glaucoma. Ophthalmology. 2014;121:1322-32.

9. Lee EJ, Lee KM, Lee SH, Kim TW. OCT angiography of the Peripapillary retina in primary open-angle Glaucoma. Invest Ophthalmol Vis Sci. 2016;57:6265-70.

10. Liu L, Jia Y, Takusagawa HL, Pechauer AD, Edmunds B, Lombardi L, et al. Optical coherence tomography angiography of the Peripapillary retina in Glaucoma. JAMA Ophthalmol. 2015;133:1045-52.

11. Suh MH, Zangwill LM, Manalastas PI, Belghith A, Yarmohammadi A, Medeiros FA, et al. Optical coherence tomography angiography vessel density in glaucomatous eyes with focal Lamina Cribrosa defects. Ophthalmology. 2016;123:2309-17.

12. Yarmohammadi A, Zangwill LM, Diniz-Filho A, Suh MH, Yousefi S, Saunders $L$, et al. Relationship between optical coherence tomography angiography vessel density and severity of visual field loss in Glaucoma. Ophthalmology. 2016;123:2498-508.

13. Yip VCH, Wong HT, Yong VKY, Lim BA, Hee OK, Cheng J, et al. Optical coherence tomography angiography of optic disc and macula vessel density in Glaucoma and healthy eyes. J Glaucoma. 2019;28:80-7.

14. Li XX, Wu W, Zhou H, Deng JJ, Zhao MY, Qian TW, et al. A quantitative comparison of five optical coherence tomography angiography systems in clinical performance. Int J Ophthalmol. 2018;11:1784-95.

15. Munk MR, Giannakaki-Zimmermann H, Berger L, Huf W, Ebneter A, Wolf S, et al. OCT-angiography: a qualitative and quantitative comparison of 4 OCTA devices. PLoS One. 2017;12:e0177059.

16. Lim CW, Cheng J, Tay ELT, Teo HY, Wong EPY, Yong VKY, et al. Optical coherence tomography angiography of the macula and optic nerve head: microvascular density and test-retest repeatability in normal subjects. BMC Ophthalmol. 2018;18:315. 
17. Jia Y, Tan O, Tokayer J, Potsaid B, Wang Y, Liu JJ, et al. Split-spectrum amplitude-decorrelation angiography with optical coherence tomography. Opt Express. 2012;20:4710-25.

18. Stanga PE, Tsamis E, Papayannis A, Stringa F, Cole T, Jalil A. Swept-source optical coherence tomography Angio (Topcon Corp, Japan): technology review. Dev Ophthalmol. 2016;56:13-7.

19. Alonzo TA, Pepe MS. Distribution-free ROC analysis using binary regression techniques. Biostatistics. 2002;3:421-32.

20. Janes $\mathrm{H}$, Longton $\mathrm{G}$, Pepe $\mathrm{M}$. Accommodating covariates in ROC analysis. Stata J. 2009;9:17-39.

21. Rao HL, Kadambi SV, Weinreb RN, Puttaiah NK, Pradhan ZS, Rao DAS, et al. Diagnostic ability of peripapillary vessel density measurements of optical coherence tomography angiography in primary open-angle and angleclosure glaucoma. Br J Ophthalmol. 2017;101:1066-70.

22. Rao HL, Pradhan ZS, Weinreb RN, Reddy HB, Riyazuddin M, Dasari S, et al. Regional comparisons of optical coherence tomography angiography vessel density in primary open-angle Glaucoma. Am J Ophthalmol. 2016;171:75-83.

23. Van Melkebeke L, Barbosa-Breda J, Huygens M, Stalmans I. Optical coherence tomography angiography in Glaucoma: a review. Ophthalmic Res. 2018;60:139-51.

24. Geyman LS, Garg RA, Suwan Y, Trivedi V, Krawitz BD, Mo S, et al. Peripapillary perfused capillary density in primary open-angle glaucoma across disease stage: an optical coherence tomography angiography study. Br J Ophthalmol. 2017:101:1261-8.

25. Chen CL, Zhang A, Bojikian KD, Wen JC, Zhang Q, Xin C, et al. Peripapillary retinal nerve Fiber layer vascular microcirculation in Glaucoma using optical coherence tomography-based microangiography. Invest Ophthalmol Vis Sci. 2016;57:OCT475-85.

26. Akil H, Huang AS, Francis BA, Sadda SR, Chopra V. Retinal vessel density from optical coherence tomography angiography to differentiate early glaucoma, pre-perimetric glaucoma and normal eyes. PLoS One. 2017;12: e0170476.

27. Yarmohammadi A, Zangwill LM, Diniz-Filho A, Suh MH, Manalastas PI, Fatehee $\mathrm{N}$, et al. Optical coherence tomography angiography vessel density in healthy, Glaucoma suspect, and Glaucoma eyes. Invest Ophthalmol Vis Sci. 2016;57:OCT451-9.

28. Rebolleda G, Perez-Sarriegui A, De Juan V, Ortiz-Toquero S, Munoz-Negrete FJ. A comparison of two optical coherence tomography-angiography devices in pseudoexfoliation glaucoma versus primary open-angle glaucoma and healthy subjects. Eur J Ophthalmol. 2018. https://doi.org/10. 1177/1120672118805882

29. Mihailovic N, Brand C, Lahme L, Schubert F, Bormann E, Eter N. Alnawaiseh M (2018) repeatability, reproducibility and agreement of foveal avascular zone measurements using three different optical coherence tomography angiography devices. PLoS One. 2018;13(10):e0206045.

30. Lei J, Pei C, Wen C, Abdelfattah NS. Repeatability and reproducibility of quantification of superficial peri-papillary capillaries by four different optical coherence tomography angiography devices. Sci Rep. 2018;8:17866.

31. Akil H, Huang AS, Francis BA, Sadda SR. Chopra V (2017) retinal vessel density from optical coherence tomography angiography to differentiate early glaucoma, pre-perimetric glaucoma and normal eyes. PLoS One. 2018; 12:e0170476.

32. Wei Y, Jiang H, Shi Y, Qu D, Gregori G, Zheng F, et al. Age-related alterations in the retinal microvasculature, microcirculation, and microstructure. Invest Ophthalmol Vis Sci. 2017:58:3804-17.

33. Schmidl D, Schmetterer L, Garhöfer G, Popa-Cherecheanu A. Gender differences in ocular blood flow. Curr Eye Res. 2015;40:201-12.

\section{Publisher's Note}

Springer Nature remains neutral with regard to jurisdictional claims in published maps and institutional affiliations.

Ready to submit your research? Choose BMC and benefit from:

- fast, convenient online submission

- thorough peer review by experienced researchers in your field

- rapid publication on acceptance

- support for research data, including large and complex data types

- gold Open Access which fosters wider collaboration and increased citations

- maximum visibility for your research: over $100 \mathrm{M}$ website views per year

At $\mathrm{BMC}$, research is always in progress.

Learn more biomedcentral.com/submissions 